\title{
Potentiometric Sensor Based on Molecularly Imprinted Polymer for Determination of Tramadol in a Biologic Fluid Model and Urine
}

\author{
Somayeh Sadat Tabatabaei ${ }^{1,2}$, Masoomeh Shirzad ${ }^{2}$, Mohammad Saber Tehrani ${ }^{1}$ and Soroush \\ Sardari $^{2 *}$ \\ ${ }^{1}$ Department of Chemistry, Islamic Azad University, Science and Research Branch, Tehran, Iran
}

${ }^{2}$ Drug Design and Bioinformatics Unit, Medical Biotechnology Department, Biotechnology Research Center, Pasteur Institute of Iran, Tehran, Iran

*Corresponding author: Soroush Sardari, Drug Design and Bioinformatics Unit, Medical Biotechnology Department, Biotechnology Research Center, Pasteur Institute of Iran, Tehran, Iran.

To Cite This Article: Somayeh Sadat Tabatabaei, Masoomeh Shirzad, Mohammad Saber Tehrani, Soroush Sardari, Potentiometric Sensor Based on Molecularly Imprinted Polymer for Determination if Tramadol in A Biologic Fluid Model and Urine. Am J Biomed Sci \& Res. 2021 - 12(3). AJBSR.MS.ID.001743. DOI: 10.34297/AJBSR.2021.12.001743.

Received: 阱 February 03, 2021; Published: 眥 March 22, 2021

\begin{abstract}
In this study, a potentiometric sensor based on a molecularly imprinted polymer (MIP) was developed for determination of tramadol. At optimized condition the electrode exhibited a Nernestian response $(30.5 \pm 1.0 \mathrm{mV} /$ decade $)$ in a concentration range of $\left(1 \times 10^{-6}\right.$ to $\left.1 \times 10^{-2} \mathrm{M}\right)$. The potential response of the electrode was constant in the $\mathrm{pH}$ range of 1.0-9.0. The electrode demonstrated a response time about $15 \mathrm{~s}$. Selectivity coefficient of the sensor with structural similarity to tramadol was evaluated by matched potential method (MPM). The electrode was examined successfully for determination of tramadol in biological fluids and urine with a good accuracy and precision
\end{abstract}

Keywords: Molecularly imprinted polymers, Potentiometric sensors, Tramadol, Urine, Response time

\section{Introduction}

Over the last few years, molecular imprinting technique has been received high attention in the field of polymer science and chemical analysis, owing to its predetermined selectivity for target molecular, high affinity and robustness [1,2]. Molecularly imprinted polymer (MIP) can be synthesized in the presence of functional monomers, template molecules and cross-linking agent by covalent, non-covalent and sacrificial spacer methods [3-5]. After removing of the template molecules from the polymerized material, binding sites of the MIP with molecular recognition properties are formed. In this condition, cavities complementary in size and shape to the template for the substance rebinding process will be formed, MIPs can be used in several applications such as chromatographic separation, catalysis facilitation, and artificial reception drug delivery [3,6-8].
Several MIP characteristics such as their stability, less cost ease of producing as compared to their biological counterparts including antibodies and enzymes, have made them to gain wide acceptance as new molecular recognition materials in chemical sensors $[9,10]$. There are various chemical sensors preparation using MIPs for molecular recognition followed by appropriate signal transduction including capacitance, conductometry and spectroscopy [11-13]. For chemical sensing, potentiometric sensors are generic and highly successful. They do not require the template molecules to diffuse through the electrode membranes for generation of membrane potentials have shown to be very promising, unlike sensors based other transduction techniques, so the MIP based potentiometric sensors are very promising and have gotten a rapid response time but still the reports of MIP based potentiometric sensor are rather rare [14-19]. 
Tramadol hydrochloride, is a synthetic analgesic with morphinelike effect causes its analgesic effect, it binding to receptors in the brain and inhibiting reuptake of norepinephrine and serotonin. Tramadol like other narcotics is a painkiller and if it is abused, may have a therapeutic plasma concentration that is in the range of 100-300 mg/l. Tramadol is rapidly and almost completely absorbed after an administration, but its absolute bioavailability is only 65-70 \% [20]. The current work, proposed an innovative method for determination of tramadol by a novel potentiometric sensor, based on molecular imprinted polymer. The precursors for preparation of imprinted polymers included methacrylic acid as functional monomer, ethylene glycol dimethacrylate as cross- linker, chloroform as solvent and tramadol as the template molecule. The influence of various parameters on the extraction efficiency of the polymer had been evaluated. Furthermore, the optimal conditions for the MIP cartridges were studied. At optimized conditions, the electrode exhibited a Nernst condition in a concentration range of $1.10^{-6}$ to $1.10^{-3} \mathrm{M}$.

\section{Materials and Methods}

Tramadol hydrochloride from Daropakhsh Co. (Iran), methacrylic acid (MMA) from Merck (Germany), ethylene glycol dimethacrylate (EGDMA), from Merck (Germany), 2,2-Azo-bisiso-butyronitrile (AIBN) (from Aldrich) (USA); all of solvents, chloroform, acetic acid, methanol from Merck (Germany). Poly vinyl chloride (PVC), dibutyl phthalate (DBP) sodium tetraphenyl borate (NaTPB), oleic acid, (OA), dioctyl phthalate (DOP) Acetophenone (AP) was used as a plasticizer and nitrobenzene (NB) were purchased from Aldrich (USA). All potentials were measured on digital Hioki 3200 multimeter Philips Saturated Calomel Reference electrode (SCE). FTIR spectra were obtained by a Nexus 870 Thermo Nicolet FTIR Spectrometer. A MP225 Metter-Toledo pHmeter was used for the $\mathrm{pH}$ adjustments.

\section{Synthesis of MIP and NIP}

The MIP was prepared by mixing tramadol ( $0.25 \mathrm{mmol}$, ) as the template, it was dissolved in $(25 \mathrm{ml})$ chloroform, and MAA (1.5 mmol) as the functional monomer, EGDMA (10 mmol) as the cross-linker, and AIBN (1.5 mmol) as the initiator in a thick-walled glass tube. The mixture was purged with nitrogen for $10 \mathrm{~min}$ and sonicated to remove dissolved oxygen. Lastly the polymerization was allowed to continue in an oil bath of $60{ }^{\circ} \mathrm{C}$ for $18 \mathrm{~h}$. The produced polymer was crushed and ground into a fine powder

and then was passed through a 200-mesh sieve. Removal of the template and unreacted monomers were performed by washing the polymer successively in methanol/acetic acid solution (10:1, v/v) for several times, each time for $4 \mathrm{~h}$, the recycle time for washing process was finished until no absorption of template at $273 \mathrm{~nm}$ was observed with a Shimadzu-UV-1700 PC spectrophotometer. Then, the polymer was washed several times with water and dried. The dried polymers were ready to use. The blank polymer, No Imprinted Polymer (NIP), was similarly prepared by omitting the imprint molecule in the same method.

\section{Electrode Preparation}

Membrane contained MIP or NIP (58 mg). NaTPB (1 mg), as additive, DOP (60 mg), as plasticizer and $3 \mathrm{mg}$ PVC was dissolved in $2 \mathrm{ml}$ of THF. A Pyrex tube with about $5 \mathrm{~mm}$ was dipped into the mixture so that a membrane thickness of $0.4 \mathrm{~mm}$ was formed. The tube was then pulled out from the mixture and kept at room temperature for about $24 \mathrm{~h}$. The tube was then filled with an internal filling solution $\left(10^{-3} \mathrm{M}\right.$ tramadol hydrochloride). The electrode was finally conditioned for $24 \mathrm{~h}$.

\section{Emf Measurements}

The following sensor was assembled for the conduction of the emf measurements. Ref. electrode $\|$ test solution |MIP membrane | internal solution | internal Ref. electrode. These measurements were preceded by the calibration of the electrode with several tramadol hydrochloride solutions.

\section{Results}

\section{Optimization of The Membrane}

The influence of membrane composition on the potential response was tested and the results shown in (Table 1). The ratio of the optimized membrane was kept constant in the optimization of membrane composition. It was found that the membrane with NaTPB and DOP provided a better response with a wider linear response range. Experiments showed that the response slop of the MIP based membrane could be improved to achieve theoretical value with the lipophilic borate. The selectivity and linearity of the membrane electrode also depends on the amount of the MIP which determined the number of the binding sites. Table 1 indicates that the membrane with $33 \mathrm{wt} \%$ of PVC, $60 \mathrm{wt} \%$ of DOP, $1.2 \mathrm{wt} \%$ of NATPB and $5.8 \mathrm{wt} \%$ of MIP showed the best performance.

Table 1: Acetophenone (AP) was used as a plasticizer.

\begin{tabular}{|c|c|c|c|c|c|c|c|c|c|c|c|}
\hline Membrane No & $\begin{array}{l}\text { MIP } \\
\text { (mg) }\end{array}$ & $\begin{array}{l}\text { PVC } \\
\text { (mg) }\end{array}$ & AP (mg) & $\begin{array}{c}\text { NB } \\
\text { (mg) }\end{array}$ & $\begin{array}{l}\text { DBP } \\
\text { (mg) }\end{array}$ & $\begin{array}{l}\text { DOP } \\
\text { (mg) }\end{array}$ & $\begin{array}{c}\mathrm{OA} \\
(\mathrm{mg})\end{array}$ & $\begin{array}{c}\text { NaTPB } \\
\text { (mg) }\end{array}$ & $\begin{array}{l}\text { KTPB } \\
\text { (mg) }\end{array}$ & $\begin{array}{l}\text { THF } \\
\text { (ml) }\end{array}$ & Slop(mV/decad) \\
\hline 1 & 5.5 & 30.5 & 60 & - & - & - & 3.5 & - & - & 2 & 3 \\
\hline 2 & 5.5 & 30.5 & 60 & - & - & - & - & 3.5 & - & 2 & - \\
\hline 3 & 5.5 & 30.5 & 60 & - & - & - & - & - & 3.5 & 2 & 2.58 \\
\hline 4 & 5.5 & 30.5 & - & 60 & - & - & 3.5 & - & - & 2 & - \\
\hline
\end{tabular}




\begin{tabular}{|c|c|c|c|c|c|c|c|c|c|c|c|}
\hline 5 & 5.5 & 30.5 & - & 60 & - & - & - & 3.5 & - & 2 & 5 \\
\hline 6 & 5.5 & 30.5 & - & - & 60 & - & - & - & 3.5 & 2 & 7.5 \\
\hline 7 & 5.5 & 30.5 & - & - & - & 59.5 & 4 & - & - & 2 & 10 \\
\hline 8 & 5.5 & 30.5 & - & - & - & 59.5 & - & 4 & - & 2 & 14 \\
\hline 9 & 5.5 & 30.5 & - & - & - & 59.5 & - & - & 4 & 2 & - \\
\hline (a) 10 & 5.8 & 33 & - & - & - & 60 & - & 1.2 & - & 2 & $30.5 \pm 1$ \\
\hline (b) 11 & 5.8 & 33 & - & - & - & 60 & - & 1.2 & - & 2 & 2.5 \\
\hline (c) 12 & - & 33 & - & - & - & 60 & - & 1.2 & - & 2 & - \\
\hline
\end{tabular}

\section{Characterization of Imprinted Polymers}

After template extraction and washing procedure, the FT-IR spectra of control molecularly imprinted polymer (MIP, unwashed MIP and also the pure tramadol were obtained. The spectra showed in (Figure 1). In the FT-IR spectra, -OH stretch (3200-3550 $\mathrm{cm}^{-1}$ ), carbonyl group stretch $\left(1730 \mathrm{~cm}^{-1}\right)$, C-O stretch $(970-1250 \mathrm{~cm}$ $\left.{ }^{1}\right)$, C-H vibration (690-900 $\left.\mathrm{cm}^{-1}\right)$, $-\mathrm{CH}$ bending (1300-1450 $\mathrm{cm}^{-1}$ ),
$\mathrm{C}=0$ stretch $\left(1720-1740 \mathrm{~cm}^{-1}\right), \mathrm{C}-\mathrm{N}$ stretch $\left(1000-1250 \mathrm{~cm}^{-1}\right), \mathrm{N}-\mathrm{H}$ group (1590-1650 $\mathrm{cm}^{-1}$ ) were observed. From this comparison it was found that presence of imprint molecule (tramadol) causes incorporation of ethylene glycol dimethacrylate in the preparation of polymer to be increased. Whereas, in case the MIP and unwashed MIP spectra are compared, the intensity of the bands in the same region are more or less the same, showing that the MIP was sufficiently leached.
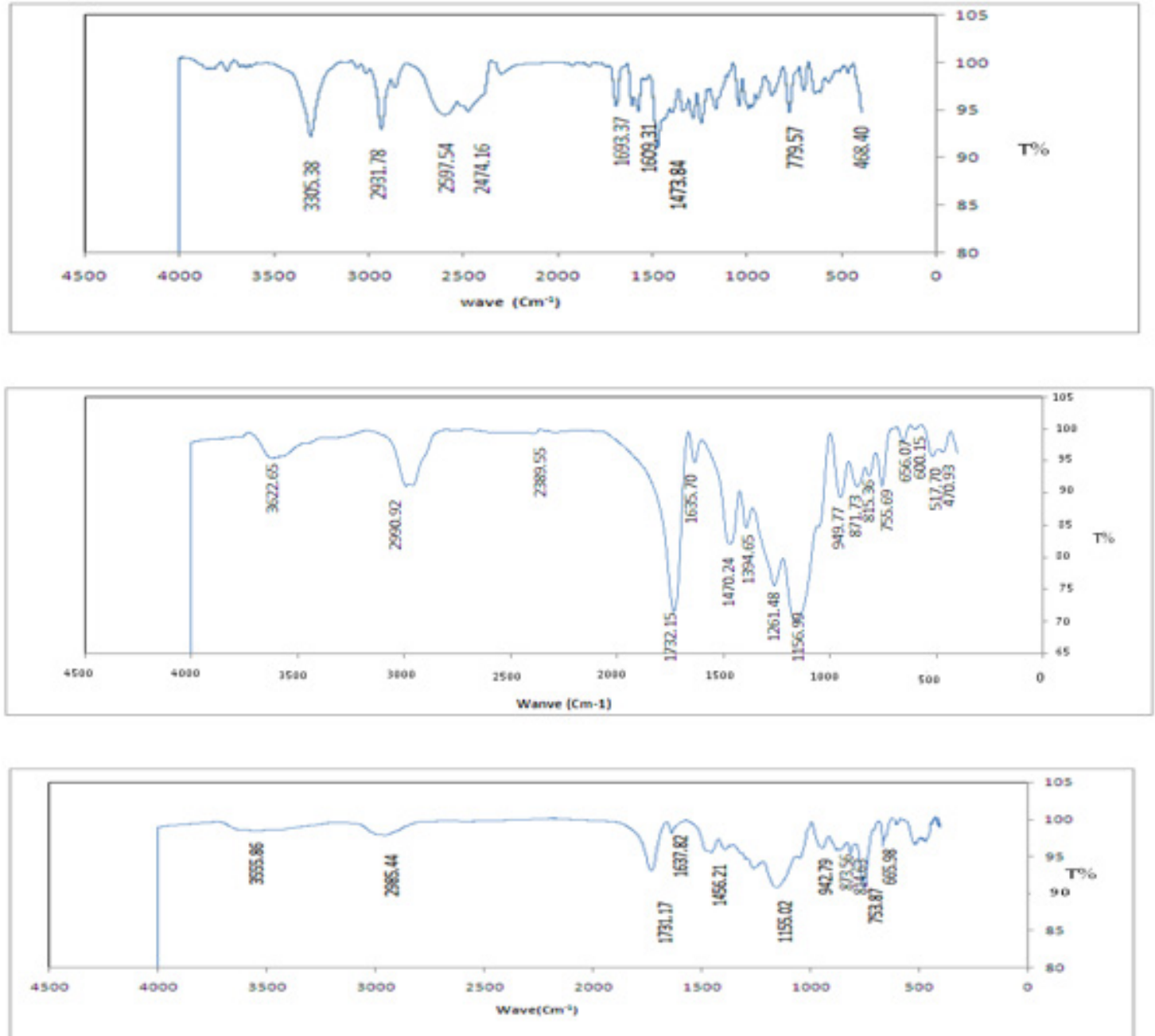

Figure 1: FT-IR Spectra of tramadol, (top), MIP (middle), and unwashed MIP (bottom) in 400-4000 $\mathrm{cm}^{-1}$ range by $\mathrm{KBr}$ tablet method. 


\section{Effect of Internal Solution}

The effect of the internal solution concentration on the potential response of the sensor was investigated. The concentration of tramadol was changed between $1.0 \times 10^{-4}$ and $1.0 \times 10^{-3} \mathrm{~mol} \mathrm{l}^{-1}$ and the potential responses of the sensor were measured. It was found that the concentration variation of the internal solution showed a significant difference in the corresponding potential response. Therefore, the $1 \times 10^{-3} \mathrm{moll}^{-1}$ internal solution which showed the best response to the target molecule was used for smooth functioning of the sensor (Figure 2).

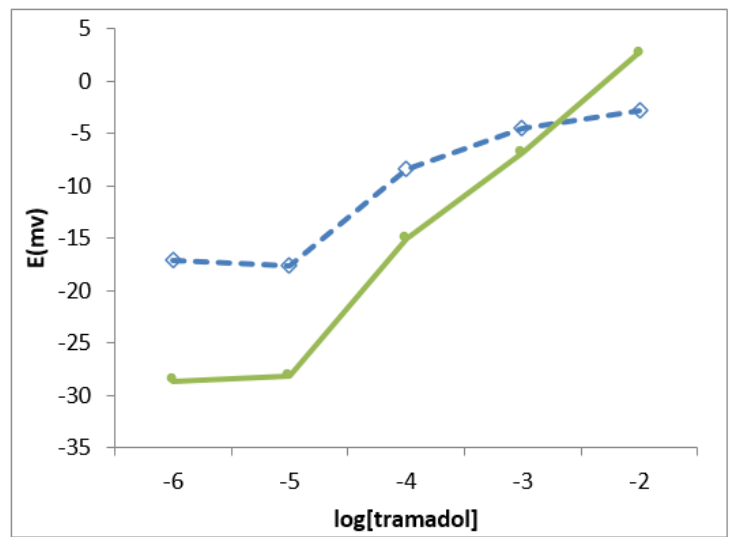

Figure 2: Effect of internal solution concentration on electrode response $\left(10^{-3} \mathrm{M}, \bullet 10^{-4} \mathrm{M}\right)$.

\section{Effect of pH}

The $\mathrm{pH}$ dependence of the membrane sensor was tested with tramadol concentration of $10^{-4} \mathrm{M}$ in the $\mathrm{pH} 1-14$ that the results shown in (Figure 3). The potential remained constant despite the $\mathrm{pH}$ change in the range of 1-8.5 indicating the applicability of this electrode in the specific pH range. In summary, the fluctuations above the pH value of 8.5 might be justified by the formation of protonated form of tramadol, which is apparently better fitted into MIP. Therefore, all the experiments were carried out at pH 7.

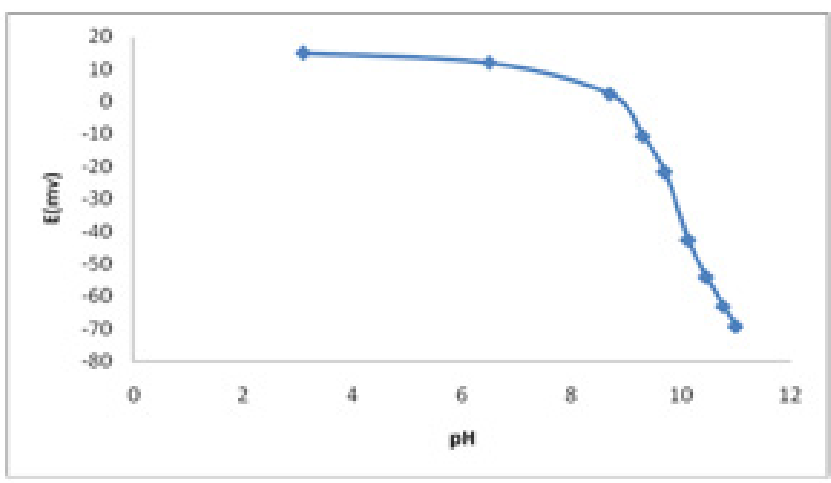

Figure 3: Effect of $\mathrm{pH}$ on the response of optimized electrode.

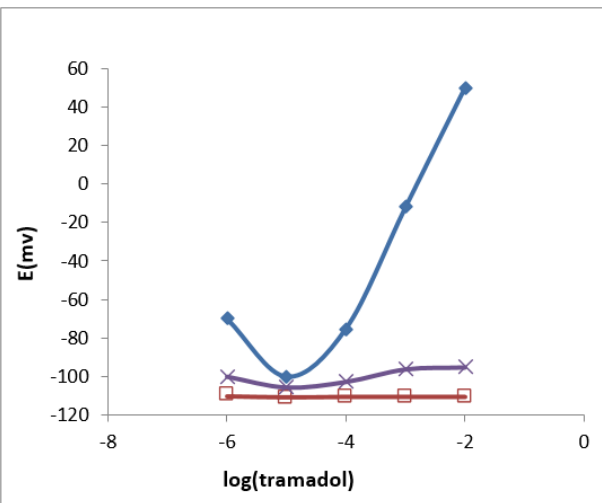

Figure 4: Calibration curve for the proposed selective electrode membrane with optimized composition based on MIP ( $\square$ ), NIP (×), and blank ( $\square)$, (with no polymer).

$\mathrm{X}$-axis is log tramadol molar concentration $\mathrm{Y}$-axis is the response $\mathrm{E}(\mathrm{mV})$ 


\section{Calibration Curve}

The potential response curves of MIP and NIP based membrane shown in (Figure 4). The MIP membrane showed a Nernstian response of $30.5 \pm 1$ mVper decade over the concentration range of $1.0 \times 10^{-6}$ to $1.0 \times 10^{-2} \mathrm{~mol} \mathrm{l}^{-1}$. However, the NIP-based and blank membranes could not be observed with NIP and blank.

\section{Response Time}

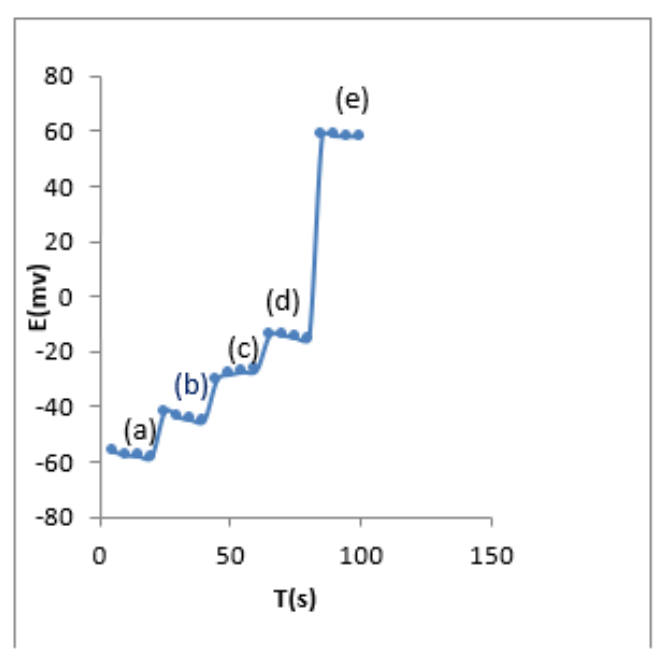

Figure 5: Dynamic response time electrode for step changes in tramadol concentration, (a) $10^{-6} \mathrm{M}$, (b) $10^{-5} \mathrm{M}$, (c) $10^{-4} \mathrm{M}$, (d) $10^{-3} \mathrm{M}$, (e) $10^{-2} \mathrm{M}$.

Response time is the average time required for the electrodes a potential within $\pm 0.1 \mathrm{mV}$ of the final steady-state potential upon successive immersion in a series of tramadol, each having a tenfold difference in concentration. The dynamic potential response with time is shown in (Figure 5) where the tramadol is changed between $1.0 \times 10^{-6}$ and $1.0 \times 10^{-2} \mathrm{~mol}^{-1}$. It can be seen that the response of the MIP sensor is rapid (15 s).

\section{Interference Studies}

Interference studies was determined by matched potential method (MPM). The coefficient describes the preference of the suggested electrode for interfering ions $\mathrm{X}$ with reference to the primary ion. It could be seen that the proposed electrode, shown high selectivity of tramadol indifferent contain. The selectivity coefficient was determined using the matched potential method for aspirin and the result was for the $\mathrm{k}^{\mathrm{MPM}}$ tramadolX, value equal to -5.397 .

\section{Potentiometric Titration}

It should be noted that the tramadol selective membrane electrode introduction not only could be used for the direct determination of the tramadol ions, but also it may have potential applications in variety of fields. We successfully applied the MIPbased electrode as an indicator electrode in potentiometric titration of $25 \mathrm{ml} 1.0 \times 10^{-4} \mathrm{~mol} \mathrm{l}^{-1}$ tramadol against $0.1 \mathrm{M}$ sodium tetraphenyl borate solution and the resulting titration curve shown in (Figure 6). The amount of tramadol in solution could be determined with this electrode.

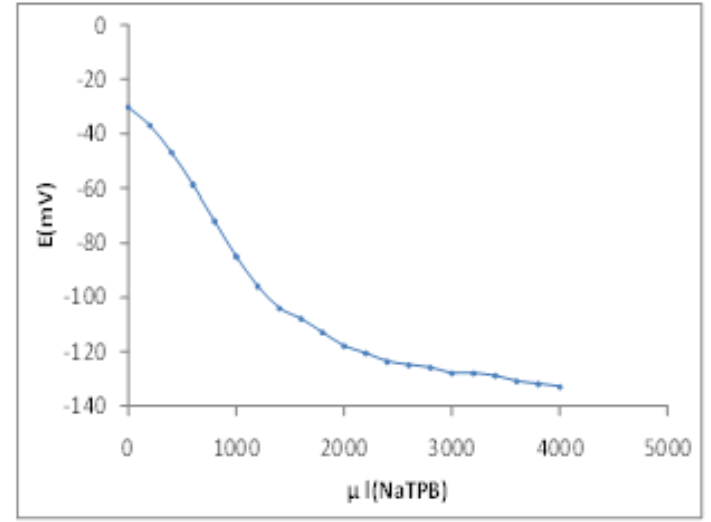

Figure 6. Potentiometric titration curves for $25 \mathrm{ml}$ of solution of tramadol with NaTPB $10^{-1}$. 


\section{Detection of Tramadol in Biologic Fluid Model}

In order to investigate the applicability of the new sensor to detect the drug in the biological fluids the drug solution was diluted with the biological fluid model sample. The tramadol content of the solution was detected by the proposed electrode. The result of recovery studies summarized in (Table 2).

Table 2: Recoveries of tramadol in biologic fluid model.

\begin{tabular}{|c|c|c|}
\hline Added Tramadol (M) & E(mV) & Recovery (\%) \\
\hline $10^{-3}$ & -12 & 83 \\
\hline $10^{-2}$ & -50 & 100 \\
\hline
\end{tabular}

\section{Detection of Tramadol from Urine Sample}

Urine sample from a healthy volunteer was collected. Different concentration of the drug was diluted with water and added to the urine sample and brought to $\mathrm{pH} 10$; then was centrifuged at $5000 \mathrm{~g}$ for $10 \mathrm{~min}$. Potentiometric analysis with proposed tramadol results and recovery studies shown in (Table 3 \& 4).

Table 3: Recoveries of tramadol in urine.

\begin{tabular}{|c|c|c|}
\hline Added Tramadol (M) & E (mV) & Recovery (\%) \\
\hline $10^{-4}$ & -73 & 97.33 \\
\hline $10^{-3}$ & -11 & 91 \\
\hline $10^{-2}$ & -47 & 94 \\
\hline
\end{tabular}

Table 4: Comparison of different methods for determination of tramadol.

\begin{tabular}{|c|c|c|c|}
\hline Method & Recovery (\%) & Working Concentration Range( $\boldsymbol{\mu g} / \mathbf{m l})$ & $10-50$ \\
\hline SPE-MIP & 94 & $10-100$ & {$[20]$} \\
\hline HPLC & 97 & $830-0.083$ & {$[23]$} \\
\hline Sensor(tramadol-TPB) & 104.4 & $83-0.083$ & - \\
\hline
\end{tabular}

\section{Discussion}

In this study, a new polymeric membrane ion-selective electrode based on MIP for tramadol has been described. The sensor can be used for measuring tramadol in urine and plasma samples. The analytical applicability of proposed sensor was checked by the determination and recovery of tramadol in urine and biologic fluid model and also titration method. Additives could decrease the membrane resistance, reduce anion interference and improve selectivity of the electrode [21]. It is notable that the experimental conditions such as the stirring or flow rate, the ionic concentration and composition of test solution, the concentration and composition of the solution to which the electrode was exposed before experiment measurement was performed, any previous usages or preconditioning of the electrode, and testing temperature have an effect on the experimental response time of sensor [22]. Interference studies method is recommended to overcome the difficulties associated with the method based on the Nicolsky-Eisenman equation [21,22]. The prepared electrode showed promising results which could be applied in improved versions to help in determination of tramadol in various solutions for acceptable analytical purposes.

\section{References}

1. Haupt K, Mosbach K (2000) Molecularly imprinted polymers and their use in biomimetic sensors. Chem Rev 100(7): 2495-25040.
2. Prasada Rao T, Kala R (2008) Potentiometric transducer based biomimetic sensors for priority envirotoxic markers--an overview. Talanta 76(3): 485-496.

3. Wulff G (2002) Chemical enzyme-like catalysis by molecularly imprinted polymers. Chem Rev 102(1): 1-28.

4. Arshady R, Mosbach K (1981) Synthesis of substrate-selective polymers by host-guest polymerization. Die Makromolekulare Chemie 182: 687692.

5. Whitcombe MJ, Rodriguez ME, Villar P Vulfson EN (1995) A new method for the introduction of recognition site functionality into polymers prepared by molecular imprinting: synthesis and characterization of polymeric receptors for cholesterol. J Am Chem Soc 117(27): 7105-7111.

6. Yahya S, Adnan S, Khalid AI (2009) Preparation of highly selective solidphase extractants for Cibacron reactive dyes using molecularly imprinted polymers. Analytical and bioanalytical chemistry 393(3):1055-1062.

7. Schirmer C Meisel H (2006) Synthesis of a molecularly imprinted polymer for the selective solid-phase extraction of chloramphenicol from honey. J Chromatogr A 1132(1-2): 325-328.

8. Vlatakis G, Andersson LI, Müller R, Mosbach K (1993) Drug assay using antibody mimics made by molecular imprinting. Nature 361(6413): 645-647.

9. Silvestri D, Barbani N, Cristallini C, Giusti P, Ciardelli G, et al. (2006) Molecularly imprinted membranes for an improved recognition of biomolecules in aqueous medium. Journal of membrane science 282(12): 284-295.

10. Ulyanova YV, Blackwell AE, Minteer SD (2005) Poly (methylene green) employed as molecularly imprinted polymer matrix for electrochemical sensing. Analyst 131(2): 257-261. 
11. Panasyuk-Delaney T, Mirsky VM, Ulbricht M, Wolfbeis OS (2001) Impedometric herbicide chemosensors based on molecularly imprinted polymers. Analytica Chimica Acta 435(1): 157-162.

12. Sergeyeva TA, Piletsky SA, Panasyuk TL, El'skaya AV, Brovko AA, et al. (1999) Conductimetric sensor for atrazine detection based on molecularly imprinted polymer membranes. Analyst (3): 124-331.

13. Jenkins AL, Yin R, Jensen JL (2001) Molecularly imprinted polymer sensors for pesticide and insecticide detection in water. Analyst (6): 126-798.

14. Blanco-Lopez MC, Lobo-Castanon MJ, Miranda-Ordieres AJ, TunonBlanco P (2004) Electrochemical sensors based on molecularly imprinted polymers. TrAC Trends in Analytical Chemistry 23(1): 36-48.

15. Agostino GD, Alberti G, Biesuz R, Pesavento M (2006) Potentiometric sensor for atrazine based on a molecular imprinted membrane. Biosensors and Bioelectronics 22(1):145-152.

16. Hutchins Rs, Bachas LG (1995) Nitrate-selective electrode developed by electrochemically mediated imprinting/doping of polypyrrole. Analytical Chemistry 67(10): 1654-1660.

17. Kamel AH, Moreira FTC, Almeida SAA, Sales MGF (2008) Novel potentiometric sensors of molecular imprinted polymers for specific binding of chlormequat. Electroanalysis 20-194.

18. Liang R, Zhang R, Qin W (2009) Potentiometric sensor based on molecularly imprinted polymer for determination of melamine in milk. Sensors and Actuators B: Chemical 141(2): 544-550.
19. Prasad K, Prathish KP, Gladis JM, Naidu GRK, Rao TP, et al. (2007) Potentiometric sensor based on molecularly imprinted polymer for determination of melamine in milk. Sensors and Actuators B: Chemical 65-123.

20. Javanbakht M, Attaran AM, Namjumanesh MH, Esfandyari-Manesh M, Akbari-Adergani B, et al. (2010) Solid-phase extraction of tramadol from plasma and urine samples using a novel water-compatible molecularly imprinted polymer. J Chromatogr B Analyt Technol Biomed Life Sci 878(20): 1700-1706

21. Silvester DS, Grygolowicz-Pawlak E, Bakker E (2010) Potentiometric determination of coextraction constants of potassium salts in ionselective electrodes utilizing a nitrobenzene liquid membrane phase. Analytica ChimicaActa, 683(1): 92-95.

22. Ganjali MR, Razavi T, Faridbod F, Riahi S, Norouzi P, et al. (2009) Application of a new tramadol potentiometric membrane sensor as a useful device for tramadol hydrochloride analysis in Pharmaceutical formulation and urine. Current Pharmaceutical Analysis 5(1): 28-33.

23. Ardakani YH, Rouini M (2007) Improved liquid chromatographic method for the simultaneous determination of plasma, urine and saliva. Journal of Pharmaceutical and Biomedical Analysis 44(5): 1168-1173. 